\title{
Design and Construction of a Prototype Solenoid Coil for MICE Coupling Magnets
}

\author{
L. Wang, H. Pan, X. L. Guo, F. Y. Xu, X. K. Liu, H. Wu, S. X. Zheng, M. A. Green Member IEEE, \\ D. R. Li, S. P. Virostek, M. S. Zisman
}

\begin{abstract}
A superconducting coupling solenoid mounted around four conventional RF cavities, which produces up to $2.6 \mathrm{~T}$ central magnetic field to keep the muons within the cavities, is to be used for the Muon Ionization Cooling Experiment (MICE). The coupling coil made from copper matrix NbTi conductors is the largest of three types of magnets in MICE both in terms of 1.5 $m$ inner diameter and about $13 \mathrm{MJ}$ stored magnetic energy at full operation current of $210 \mathrm{~A}$. The stress induced inside the coil assembly during cool down and magnet charging is relatively high. In order to validate the design method and develop the coil winding technique with inside-wound SC splices required for the coupling coil, a prototype coil made from the same conductor and with the same diameter and thickness but only one-fourth long as the coupling coil was designed and fabricated by ICST. The prototype coil was designed to be charged to strain conditions that are equivalent or greater than would be encountered in the coupling coil. This paper presents detailed design of the prototype coil as well as developed coil winding skills. The analyses on stress in the coil assembly and quench process were carried out.
\end{abstract}

Index Terms-Superconducting magnet, stress analysis, winding progress, quench

\section{INTRODUCTION}

$\mathrm{T}$ HE superconducting coupling solenoid mounted around four conventional RF cavities, which produces up to $2.6 \mathrm{~T}$ central magnetic field to keep the muons within the cavities, is to be used for the Muon Ionization Cooling Experiment (MICE) [1]. The coupling coil made from commercial copper based $\mathrm{Nb}$-Ti conductors is the largest of three types of magnets in MICE in term of $1.5 \mathrm{~m}$ in inner diameter [2][3]. It is $285 \mathrm{~mm}$ long and $110 \mathrm{~mm}$ thick, and has 96 layers with 166 turns per layer. It produces $7.3 \mathrm{~T}$ peak field in the coil and has about $13 \mathrm{MJ}$ stored magnetic energy at full operation current of $210 \mathrm{~A}$.

Manuscript received 20 October 2009. This work was supported by Funds of cryogenics and superconductivity technology innovation project under "985-2 Plan" of Harbin Institute of Technology, China and by the Office of Science, US Department of Energy under DOE contract DE-AC02-05CH11231.

L. Wang was with the Institute of Cryogenics and Superconductivity Technology, HIT, Harbin 150001, China. She is now with Shanghai Institute of Applied Physics, Shanghai 201204, China (phone: 86-21-33932552, e-mail: wangli_icst@hit.edu.cn).

H. Pan, X. L. Guo, F. Y. Xu, X. K. Liu, H. Wu, S. X. Zheng are with the Institute of Cryogenics and Superconductivity Technology, Harbin Institute of Technology, Harbin 150001, China (panheng@hit.edu.cn).

M. A. Green, D. R. Li, S. P. Virostek, M. S. Zisman are with Lawrence Berkeley National Laboratory, Berkeley, CA, 94720 USA (magreen@lbl.gov).
Because of high magnetic field and large size, the stress induced inside the coil assembly during cool down and full charge is relatively high. The severe stress and strain situation is the potential to cause the magnet quench or training during charging [4].

There will be evenly eleven joints in each coupling coil winding because of length limitation of each SC wire provided by the vendor. In consideration of tight space, coil size and direct cooling method for the magnet, the $\mathrm{SC}$ joints are to be wound inside the coil. Both the resistance at $4.2 \mathrm{~K}$ and high magnetic field, and the strength of the SC spices are concerns which may lead to the coil quench or failure. The approaches to make the SC joints, to insulate them and to wind them into the coil need to be developed and tested experimentally [5].

The coupling coil is designed to be passively protected by sub-dividing the coil into eight parts once quench [6]. Each coil sub-division will have a diode and resistor across it and will be attached onto the coil cold mass. The magnetic field around the diodes generated by the coupling coil at $210 \mathrm{~A}$ is in the range from $1.5 \mathrm{~T}$ to $2.5 \mathrm{~T}$. Performance of the cold diodes used for quench protection such as the forward voltage is directly related to the work temperature and the magnetic field around it. Before mounting the quench protection assembly in the coupling coil, the performance of the quench sub-division has to be tested.

Therefore, in order to practice the worst strain case in the coupling coil, to validate the design method and to develop the fabrication technique required for the coupling coil including the coil wet lay-up winding skill and inside-wound SC splice soldering, two test coils were designed, built and to be cryo-tested by ICST [7]. A small test coil is $350 \mathrm{~mm}$ inner diameter with one-quarter of thickness (only 24 layers) and full length of $285 \mathrm{~mm}$ as the coupling coil. A prototype coil is the same as the coupling coil except with one-quarter length of the coupling coil (42 turns per layer). All the skills to be used for fabricating the coupling coil will be performed on the two test coils.

The prototype coil is expected to be charged to the equivalent or greater strain state than the coupling coil would encounter, to be conducted a full scale test of the quench protection circuits with four sub-divisions across the coil composed of the cold diodes and the resistors, to verify the SC joint soldering technique and the joint break strength, and to gain training experience.

This paper presents the design and construction of the prototype coil including developed coil winding skills. The analyses on stress in the coil assembly and quench process were carried out. 


\section{Design OF The PROTOTYPE COIL}

\section{A. Basic Parameters and Load Lines}

The basic parameters for the prototype coil and the coupling coil are compared in Table I. The prototype coil is the same as the coupling coil except with one-quarter length of the coupling coil (42 turns per layer). The prototype coil is made from the same commercial copper stabilized NbTi conductors as those used for the coupling coil.

TABLE I. BASIC PARAMETERS OF COILS

\begin{tabular}{ccc}
\hline \hline Parameters & Prototype Coil & Coupling Coil \\
\hline Coil Length (mm) & $72(71.25)^{*}$ & 285 \\
Coil Inner Radius (mm) & 750 & 750 \\
Coil Thickness (mm) & $102.5(100)$ & $102.5(110)$ \\
Number of Layers & 96 & 96 \\
No. Turns per Layer & $42(41)$ & 166 \\
Design/Operation Current (A) & 350 & 210 \\
Magnet Self Inductance (H) & $50.813(48.6)$ & 591.8 \\
Storage energy (MJ) & $3.112(3.0)$ & 13.0 \\
Peak Induction in Coil (T) & $6.54(6.49)$ & 7.32 \\
Coil Temperature Margin (K) & $\sim 0.8$ & $\sim 0.8$ \\
\hline \hline
\end{tabular}

* Practical measured value for the prototype coil

The load line of the prototype coil by comparison with that of the couple coil is shown in Fig. 1. At the design current 350 A of the prototype coil and 210 A of the coupling coil, the temperature margin for both coils are about $0.8 \mathrm{~K}$. The prototype coil is expected to experience the same or higher level of stress than the coupling coil does at its design current. At the ideal condition (the temperature margin is $0 \mathrm{~K}$ ), the prototype coil can be charged to 401A.

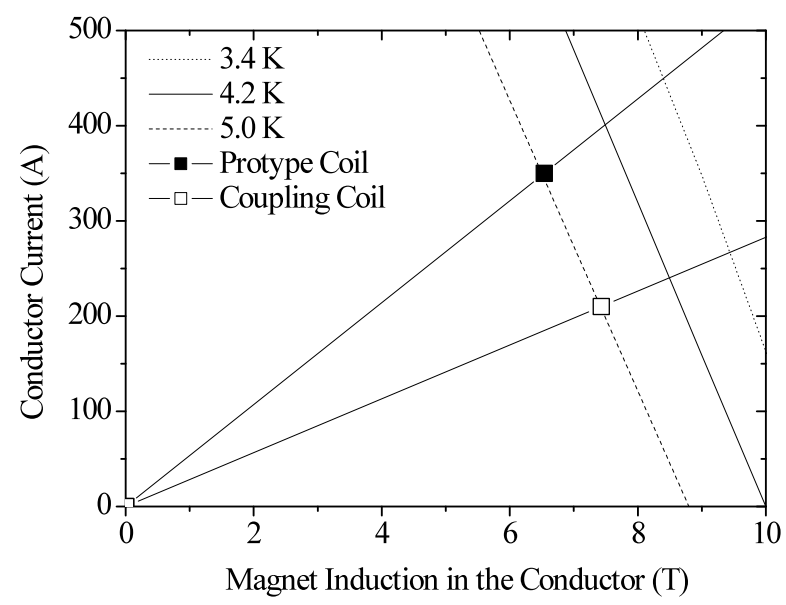

Fig. 1. The load lines of prototype coil and coupling coil

\section{B. Magnetic Field}

Fig. 2 show the magnetic field generated by the prototype coil. The cold diodes used for the quench protection are located over a field from $1.8 \mathrm{~T}$ to $3.0 \mathrm{~T}$, which is at a little worse condition than those $(1.5 \mathrm{~T}$ to $2.5 \mathrm{~T})$ for the coupling coil. The coil central field is $0.66 \mathrm{~T}, 1.11 \mathrm{~T}$ and $1.27 \mathrm{~T}$, respectively at operation current of $210 \mathrm{~A}, 350 \mathrm{~A}$ and $400 \mathrm{~A}$, and the peak field on the coil is $3.92 \mathrm{~T}, 6.54 \mathrm{~T}$ and $7.49 \mathrm{~T}$.

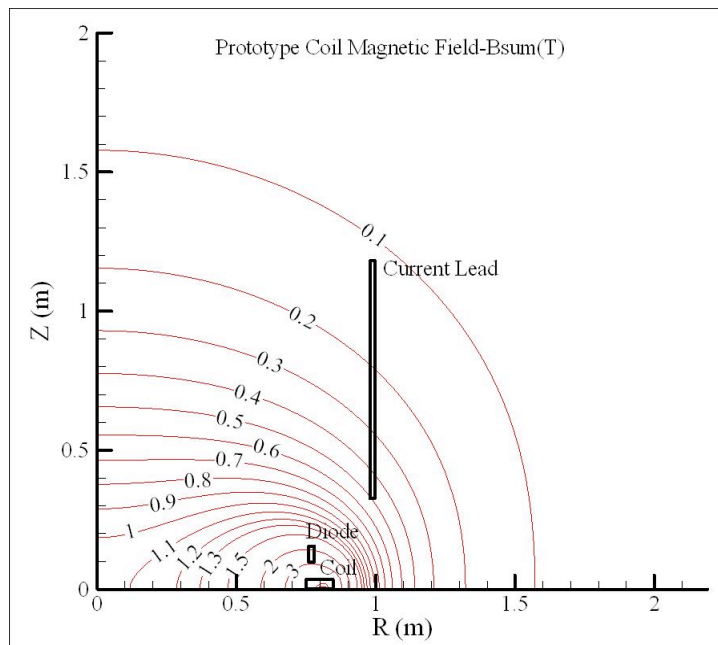

Fig. 2. Magnetic field generated by the prototype coil

\section{Stress Distribution in the Coil Assembly}

The cross section of the prototype coil assembly is shown in Fig. 3. The basic structure and materials of the prototype coil assembly are the same as those of the coupling coil. The coil assembly includes the epoxy impregnated coil, the mandrel, the banding, G-10 insulations and the cover plate. The mandrel and the cover plate are made of 6061-T6 aluminum, and the banding is made from stainless steel wire with diameter of $1.2 \mathrm{~mm}$. A finite element model (FEA) was established to calculate the stress and strain in the prototype coil assembly during the processes of coil winding, cooling down and full charging. The prototype coil winding didn't adopt the slip planes and all the components were glued together in the simulation. The winding pre-tension is set as 59 $\mathrm{MPa}$ on the conductor and $60 \mathrm{MPa}$ on the banding for the prototype coil, while $60 \mathrm{MPa}$ on the conductor and $60 \mathrm{MPa}$ on the banding for the coupling coil. The element birth and death technique and the multi-load technology were applied for the stress simulation exactly same as those for the coupling coil [4].

Fig. 4 and Fig. 5 show the stress states at the centre of prototype coil along the radial direction after cooled down to $4.2 \mathrm{~K}$ and charged to its design current of $350 \mathrm{~A}$, respectively. The data symbols in Fig. 4 and 5 have the meaning as follows: "1-3" mean hoop stress, radial stress and Von Mises stress of the coupling coil without slip planes; "4-6" represent hoop stress, radial stress and Von Mises stress of the prototype coil. The trends of the stresses in the prototype coil and the coupling coil are similar, which indicate that the prototype coil can be used for simulating the coupling coil in terms of the stress and strain state. TABLE II shows the various peak stresses in the prototype coil at different stages compared with those in the coupling coil. After charged to full current, the tensile hoop stress on the outmost layers and the radial compression stress on the innermost layers are very closer. 
The peak shear stress and the peak Von Mises of the prototype coil are a little lower than that of the coupling coil. In general the stress lever in the prototype coil is almost equivalent to that in the coupling coil.

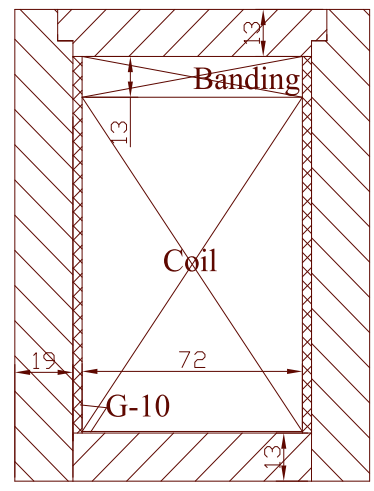

Fig. 3. Cross section of the prototype coil

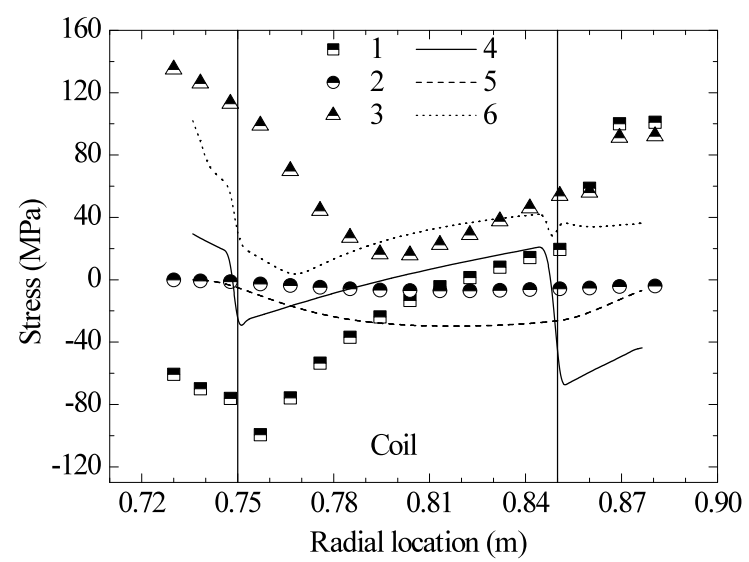

Fig.4. Stresses in the centre of the prototype coil along the radial direction after cool down to $4.2 \mathrm{~K}$ compared with coupling coil

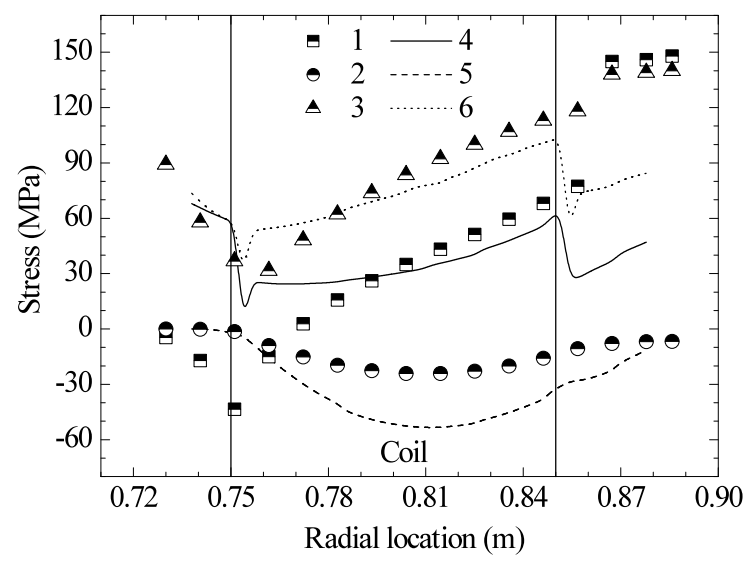

Fig. 5. Stresses in the centre of the prototype coil along the radial direction after charged to $350 \mathrm{~A}$ compared with coupling coil at $210 \mathrm{~A}$

\section{Quench Process and Protection Circuit}

The prototype coil is designed to be passive quench protected same as the coupling coil. The technology of subdivision and quench-back is adopted to reduce the inner voltage and the hot-spot temperature. The quench protection of the prototype coil is 4-sectioned. Each sub-section consists of a pair of back-to-back diodes and a $10 \mathrm{~m} \Omega$ resistor made of stainless steel. The quench simulation code developed for the MICE coupling coil is used to simulate the quench process of the prototype coil. The semi-empirical model can give a rough estimate of the hot spot temperature and the internal voltage in the coil during quench process [5]. The initiate current of the quench simulation are set as the design current of $350 \mathrm{~A}$. The quench propagation velocities are calculated as $0.22 \mathrm{~m} / \mathrm{s}, 0.30$ $\mathrm{m} / \mathrm{s}$ and $10.08 \mathrm{~m} / \mathrm{s}$, respectively in the radial, the axial and the transverse directions if assuming the average field is $4.0 \mathrm{~T}$. The peak hot spot temperature is calculated about $110 \mathrm{~K}$. The peak internal voltage is about $1900 \mathrm{~V}$, less than $2 \mathrm{kV}$ as required.

TABLE II. STRESS IN COILS

\begin{tabular}{ccccccc}
\hline \multirow{2}{*}{ Parameter (MPa) } & \multicolumn{2}{c}{ Pre-winding } & \multicolumn{2}{c}{ Cooling } & \multicolumn{2}{c}{ Charging } \\
& $\mathbf{P}^{*}$ & $\mathbf{C}^{*}$ & $\mathbf{P}$ & $\mathbf{C}$ & $\mathbf{P}$ & $\mathbf{C}$ \\
\hline Hoop & $51.7^{\#}$ & $57.6^{\#}$ & $-34.6^{* *}$ & $-115^{* *}$ & $63.4^{\#}$ & $68.8^{\#}$ \\
Radial & $-2.05^{* *}$ & $-4.47^{* *}$ & $-5.08^{* *}$ & $-3.67^{* *}$ & $-3.73^{* *}$ & $-2.35^{* *}$ \\
Max. Shear & 5.38 & 4.8 & 39.7 & 57.3 & 34.1 & 47.6 \\
Max.Von Mises & 81.6 & 130 & 65 & 115 & 102 & 119 \\
\hline \hline
\end{tabular}

*P is prototype coil and $\mathrm{C}$ is the coupling coil, ** Stress value is on the innermost layer, "Stress value is on the outmost layer.

\section{Construction OF Prototype CoIl Assembly}

A set of winding system for the solenoid coils was built in ICST. The winding system mechanically consists of a winding machine, an automatic guider, a tension adjusting mechanism, a dereeler and a control rack. The developed technology for the winding machine includes variable winding speed, wire alignment control with high accuracy, and constant tension control.

The prototype coil was wound with a wet winding process using Stycast epoxy. The skills developed during the coil winding process involve wet lay-up winding, layer-to-layer transition, quench protection lead bringing out, SC splice soldering and winding, electrical insulation, banding and so on. Various measurement and electrical checks were conducted including turn density, layer-to-layer space, resistance and coil-to-ground insulation.

Electrical insulations were applied between the coil to ground or mandrel, between coil layers, and between the coil and banding. For ground insulations, two layers of G-10 sheets with $0.5 \mathrm{~mm}$ of thickness each were wrapped onto the cylindrical 6061-aluminum mandrel with Stycast epoxy cured by Catalyst 24LV. The coil end insulation consists of two G-10 plates with a total thickness of $3 \mathrm{~mm}$ that were glued onto end plates of the coil mandrel. The insulations between layers are composed of fiberglass cloth and epoxy. Once the first layer is wound, the fiberglass cloth with $0.1 \mathrm{~mm}$ of thickness is wrapped over it, and then to brush the epoxy and winding the conductor for the next layer. The thickness per layer is controlled within $1.20 \mathrm{~mm}$ and should be evenly. Considering the layer-to-layer voltage of the prototype coil is 
only one-fourth of the MICE coupling coil, in order to shorten winding period, the fiber glass cloth was only put every 12 layers.

Upon completion of the coil winding process, the banding was wound around the outmost layer of the coils. The banding with $60 \mathrm{MPa}$ pre-tension on the coil will provide some hoop force support and ensure the coil is tightly packed when it is cooled down. The banding is made from 4 layers of stainless steel wire with $1.7 \mathrm{~mm}$ diameter. Its starting end and the tail end were connected together by soldering in order to maintain the tension. The coil was further insulated by two layers of 0.5 $\mathrm{mm}$ thick G-10 sheets with epoxy before banding. Two layers of Kapton film with a thickness of $0.02 \mathrm{~mm}$ were glued into the corners of mandrel end plates and G-10 insulations in order to enhance the electrical insulation in those regions. After banding, the cover plate was welded onto the two mandrel end plates by MIG welding method using 5356 aluminum welding rod, and then the cooling tubing and the helium vessels were welded by turns. The welding technology was studied before welding in order to keep the temperature inside the coil lower than $130 \mathrm{oC}$.

There are four up-down type SC joints with 1-m long overlap length in the coil, which soldered using $\mathrm{Ag} 3.5 \mathrm{Sn} 96 \mathrm{Cu} 0.5$ and wound at one end of the coil on the layer of 21, 40, 48 and 77. There are three quench bring-out leads from the layer of 24,50 and 72 for the coil quench protection circuit. They were all insulated by kapton tape using half-overlap winding method.

During the coil winding, the layer-to-layer thickness was checked indirectly by measuring the coil perimeter, and the turn-to-turn insulation was monitored by measuring the coil resistance. The Hi-pot test was always used to check the coil-to-ground insulation no less than $5 \mathrm{kV}$ and the leak current should be less than $50 \mu \mathrm{A}$. The coil layer-to-layer thickness and the turn-to-turn thickness are respectively 0.050 $\mathrm{mm}$ and $0.066 \mathrm{~mm}$. The outer diameter of the wound coil is $1701 \mathrm{~mm}$ and the turns per layer are 41 . The coil thickness is $100 \mathrm{~mm}$ and the length is $71.25 \mathrm{~mm}$. The winding pre-tension for the conductors is $59 \mathrm{MPa}$.

When the coil assembly was completed and was performed the electrical insulation check, the quench protection system was attached onto the outer surface of the coil case as shown in Fig. 6. A pair of 630A current leads was connected with the coil leads by soldering. After wrapped with 50 60 layers of MLI, the whole coil cold mass was installed into the test cryostat.

The cool down for the prototype coil was carried out at the end of this April, and the coil became superconducting (around 8 9K). However, it could not be cooled down further to liquid helium temperature so that it could not be charged because most of the cooling fluid went back to the gas helium return circuit from the 500L LHe dewar through a co-axial transfer line. The cryo-test system needs to be updated in order to fulfill test of coils. The upgrade system should allow all the cooling flow from the refrigerator J-T circuit going through the coil cooling circuit. The performance test of the large coil will be carried out further.
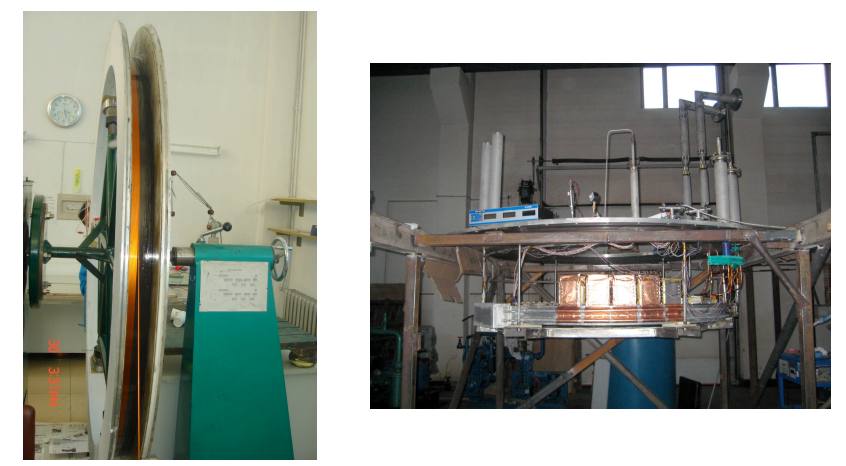

Fig. 6. Coil winding and coil assembly

\section{CONCLUSION}

A prototype superconducting coil was developed by ICST for the MICE experiment and expected to be charged to the equivalent or greater strain state than the MICE coupling coil would encounter, to be conducted a full scale test of the quench protection circuit with four sub-divisions across the coil composed of the cold diodes and the resistors, to verify the SC joint soldering technique and the joint break strength, and to gain training experience. The cool down for the prototype coil was done at the end of this April, and it became superconducting, however, the cryo-test system needs to be updated in order to fulfill further performance test of the coil.

\section{ACKNOWLEDGMENT}

The authors would like to thank the experts CHEN Hao-shu and YI Chang-lian from Beijing China, and Prof. LV Shi-xiong from HIT Harbin for their technical assistance.

\section{REFERENCES}

[1] G. Gregoire, G. Ryckewaert, L. Chevalier, et al. "MICE and International Muon Ionization Cooling Experiment Technical Reference Document" [Online]. Available: http://hep04.phys.itt.edu/cooldemo.

[2] Institute of cryogenics and superconductivity Technology, "Muon Ionization Cooling Experiment Coupling Solenoid Magnet Engineering Design Report," (Unpublished) Harbin Institute of Technology, China, Dec. 2008.

[3] L. Wang, F. Y. Xu, H. Wu, et al. "Magnetic and Cryogenic Design of MICE Coupling Solenoid Magnet System", IEEE Transactions on Applied Superconductivity 19, No.3. pp. 1344-1347, 2009.

[4] L. Wang, H. Pan, X. K. Liu, et al. "Effects of Slip Planes on Stresses in MICE Coupling Solenoid Coil Assembly", to be submitted to MT21, HeFei, Oct.18-23, 2009.

[5] F. Y. Xu, H. Pan, et al. "Measurement of Resistance and Strength of Conductor Splices in the MICE Coupling Magnets", to be published in Advances in Cryogenic Engineering 55, AIP Press, Melville NY (2010)

[6] X. L. Guo, F. Y. Xu, L. Wang, et al. "Quench Protection for the MICE Cooling Channel Coupling Magnet", IEEE Transactions on Applied Superconductivity 19, No. 3. pp. 1360-1363, 2009.

[7] L. Wang, H. Pan, F. Y. Xu, et al. "Design and Construction of Test Coils for MICE Coupling Solenoid Magnet", IEEE Transactions on Applied Superconductivity 19, No.3. pp. 1340-1343, 2009. 